\title{
Comparative study on the performance improvement of photovoltaic panel with passive cooling under natural ventilation
}

\author{
Hongbing Chen*, Xilin Chen, Sizhuo Li, Hanwan Ding \\ School of Environment and Energy Engineering, Beijing University of Civil Engineering and Architecture, Beijing 100044 China
}

\begin{abstract}
Many researchers employed air or water for active cooling of PV to achieve higher electrical efficiency, but additional energy consumption for air or water circulation may reduce the net power output or even the PV power output could not afford the energy consumption. Therefore, this paper provided a study on the electrical performance improvement of PV panel with passive fin cooling under natural ventilation. Comparative experimental study on PV panels with and without fin cooling was carried out to investigate the effect of PV panel inclination, solar radiation, and ambient temperature as well as wind velocity on the electrical efficiency and power output. The study showed that there existed a PV inclination resulting in the minimum electrical efficiency and/or the maximum power output. Higher intensity of solar radiation led to lower PV electrical efficiency. The PV electrical efficiency decreased in linear with the increasing ambient temperature. Higher wind velocity led to better fin cooling and consequently better PV electrical performance. The average electrical efficiency of PV panel with fins was $0.3 \sim 1.8 \%$ higher than that of PV panel without fins and the average power output of PV panel with fins was $1.8 \sim 11.8 \%$ higher than that of PV panel without fins under various conditions in this study.
\end{abstract}

Keywords: PV panel, passive cooling, electrical efficiency, cooling fins

\section{Introduction}

With the rapid economic development, energy demand and consumption has been sharply increasing in the past two decades. Fossil fuel reserve has been proven to be very limited, therefore, the development and utilization of renewable energy becomes more and more important. Solar energy, as a green and renewable energy, has been widely used for solar-electricity generation with photovoltaic (PV) panel in recent years. In 2012, the global PV production was $36 \mathrm{GW}$ and $63.9 \%$ of them were produced in China. PV products are mainly made of c-Si (crystalline silicon) and the electrical efficiency of commercial PV products is mostly less than 20\% [1]. Many studies found that PV cell working temperature had a great impact on the solar-to-electricity conversion efficiency [1], [2]. The increased radiation on PV cells was good for electricity production, but it would also increase the cell temperature, which limited the heat-toelectricity conversion. PV cells utilized a small fraction of the incident solar radiation to produce electricity and the remainder was turned mainly into waste heat in the cells and substrate, raising the PV temperature and hence the efficiency of the module dropped. The higher PV cell temperature was, the lower the electrical efficiency would be. The temperature coefficients were quite different for various types of PV modules: -0.4 to $-0.5 \% / \mathrm{K}$ for $\mathrm{Mc}-\mathrm{Si}$ (monocrystalline silicon) and Pc-Si (polycrystalline silicon) [3]-[5], -0.1 to $-0.26 \% / \mathrm{K}$ for A-Si (amphous silicon) [6], -0.23 for A-Si/Mc-Si hybrid [7] and -0.4 to $-0.6 \% / \mathrm{K}$ for PV/T (PV/Thermal) system [8]-[11].

Many studies of active PV cooling, employing air [8], water [9] and/or refrigerant [10]-[12] to extract

\footnotetext{
* Manuscript received May 13, 2014; revised July 26, 2013.

Corresponding author: Hongbing Chen; Tel.: +86-10-6832-2517 ; E-mail address: chenhongbing@bucea.edu.cn doi: $10.12720 /$ sgce.3.4.374-379
} 
heat from PV and combining PV panel with heat storage or heat pump for PV/T system, have been carried out to improve PV energy performance. But those systems consumed extra energy to drive the cooling fluid, and the improvement of net electricity production by active cooling was slight compared with the extra energy consumption for fan and pump. Passive cooling with no extra energy consumption could be an option to improve PV performance even the cooling effect and energy improvement could not be as good as expected. Therefore, this paper provided a study on the electrical performance of PV panel with passive fin cooling under natural ventilation.

\section{Description of Testing Rig}

The PV panel (shown in Fig. 1) consisted of 36 PV cells, made of polycrystalline silicon. The total aperture area and PV cell area were $0.865 \mathrm{~m}^{2}$ and $0.81 \mathrm{~m}^{2}$, respectively. For passive cooling, aluminum alloy sheet $(0.8 \mathrm{~mm}$ thick) was made into the U-shape and L-shape units, acting as cooling fins of the PV panel, and those units were pasted evenly on the back of PV panel with good thermal-conductive glue under pressure control to provide a good contact between the PV panel and the cooling fins. This enabled a good heat transfer from the PV panel to the fins. Two PV panels, one with cooling fins and one without cooling fins, were developed for the investigation of electrical performance difference. Under the radiation of $1000 \mathrm{~W} / \mathrm{m}^{2}$ and the ambient temperature of $25{ }^{\circ} \mathrm{C}$, the $\mathrm{PV}$ panel had an open circuit voltage of $21.55 \mathrm{~V}$ and a short circuit current of $6.55 \mathrm{~A}$. The peak power output was $100 \mathrm{~W}$ with a reference electrical efficiency of $12.9 \%$. The list of the testing devices was shown in Table 1.

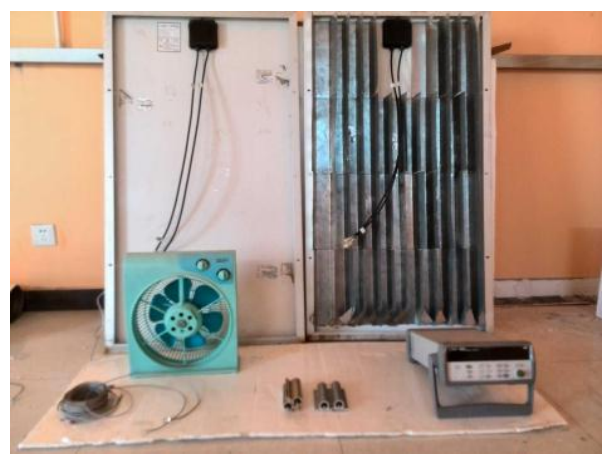

Fig. 1. PV panels with and without cooling fins.

Table 1. List of testing devices

\begin{tabular}{llll}
\hline \hline Item & Device & Quantity & Location \\
\hline 1 & Temperature sensor (Type 18B20, China) & 14 & PV panel \\
2 & Pyranometer (TBQ-2, China) & 1 & The same tilt surface beside PV panel \\
3 & Anemoscope (AVM-01, China) & 2 & Beside the cooling fins \\
4 & Data logger (Agilent 34970A, USA) & 2 & Indoor workbench \\
\hline \hline
\end{tabular}

Table 2. List of testing modes

\begin{tabular}{lllll}
\hline \hline Mode & Radiation $(\mathrm{W} / \mathrm{m} 2)$ & Wind velocity $(\mathrm{m} / \mathrm{s})$ & Ambient temperature $\left({ }^{\circ} \mathrm{C}\right)$ & PV inclination $\left({ }^{\circ}\right)$ \\
\hline A & 437 & 3 & 36 & $30,45,60$ \\
B & 500 & 3 & $43,45,46,49,50,53$ & 60 \\
C & 483 & $1,2,3$ & 36 & 60 \\
D & $299,331,380,414,442,483$ & 3 & 36 & 60 \\
\hline \hline
\end{tabular}

The testing was carried out at Beijing University of Civil Engineering and Architecture, China. The experimental rig was placed on the roof of Building No. 2 with PV panel exposed to sunshine directly not being in shade. PV panel inclination was controlled manually by regulating the holder at the back of PV panel. The pyranometer was mounted at the same tilt surface beside PV panel and changed the tilt angle together with PV panel to measure the solar radiation on the front surface of PV panel. Adhesive thermocouples were pasted on the front and back surface of PV panel and the cooling fins for monitoring temperature variation. The list of testing modes was shown in Table 2. 


\section{Results and Discussions}

\subsection{Effect of $P V$ panel inclination on electrical efficiency and power output}

The investigation on the effect of PV panel inclination on the electrical efficiency and power output was carried out based on the testing mode A. Fig. 2 showed the variation of PV electrical efficiency under different inclination of PV panel. It can be seen from Fig. 2 that the electrical efficiency decreased to the lowest point and then increased with the increasing PV panel inclination. For PV panel with fins, the electrical efficiency was $17.2 \%$ responding to the inclination of $30^{\circ}$. It decreased with the increasing inclination and reached $16.1 \%$ at the inclination of $45^{\circ}$. After that, the electrical efficiency turned to increase and reached $16.9 \%$ as the inclination increased to $60^{\circ}$. The average electrical efficiency was $16.8 \%$. For PV panel without fins, the electrical efficiency was $16.1 \%$ responding to the inclination of $30^{\circ}$. It decreased with the increasing inclination and reached $13.7 \%$ at the inclination of $45^{\circ}$. After that, the electrical efficiency turned to increase and reached $16.8 \%$ as the inclination increased to $60^{\circ}$. The average electrical efficiency was $15.5 \%$. The PV cooling fins led to an average efficiency increase by $1.3 \%$.

Fig. 3 showed the variation of power output under different inclination of PV panel. It can be seen from Fig. 3 that the power output increased firstly and then decreased with the increasing PV panel inclination. For PV panel with fins, the power output was $59 \mathrm{~W}$ responding to the inclination of $30^{\circ}$. It increased with the increasing inclination and reached $62 \mathrm{~W}$ at the inclination of $45^{\circ}$. After that, the power output turned to decrease and reached $58.1 \mathrm{~W}$ as the inclination increased to $60^{\circ}$. The average power output was $59.7 \mathrm{~W}$. For PV panel without fins, the power output was $55.2 \mathrm{~W}$ responding to the inclination of $30^{\circ}$. It increased with the increasing inclination and reached $60.5 \mathrm{~W}$ at the inclination of $45^{\circ}$. After that, the power output turned to decrease and reached $58 \mathrm{~W}$ as the inclination increased to $60^{\circ}$. The average power output was $57.9 \mathrm{~W}$.

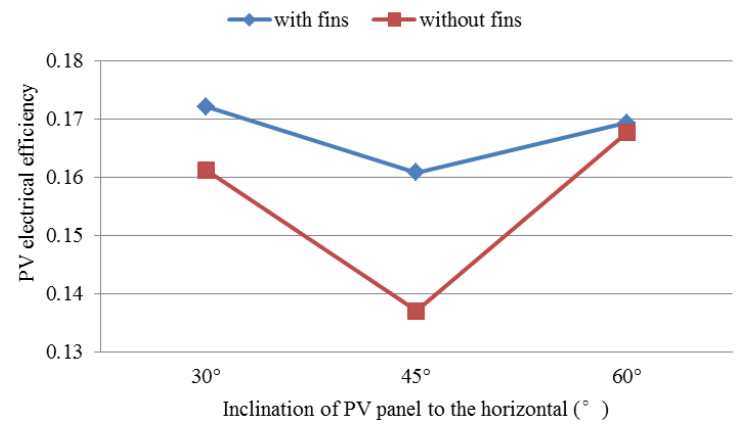

Fig. 2. Variation of electrical efficiency with PV panel inclination.

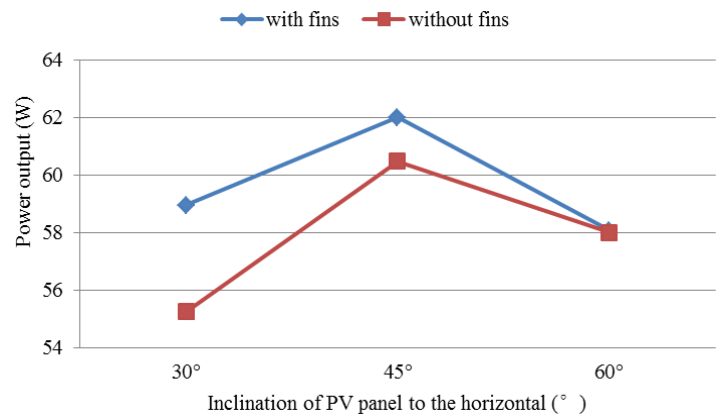

Fig. 3. Variation of power output with PV panel inclination.

\subsection{Effect of ambient temperature on electrical efficiency and power output}

The investigation on the effect of ambient temperature on the electrical efficiency and power output was carried out based on the testing mode B. Since the tested PV panels were installed on the roof, the ambient temperature was higher than air temperature due to light reflection of roof. Fig. 4 showed the variation of PV electrical efficiency under different ambient temperatures. It can be seen from Fig. 4 that the efficiency decreased with the increasing ambient temperature. As the ambient temperature increased from $42.8{ }^{\circ} \mathrm{C}$ to $52.8{ }^{\circ} \mathrm{C}$, the electrical efficiency decreased from $15.9 \%$ to $14.6 \%$ for PV panel with fins, while from $15.7 \%$ to $14.3 \%$ for PV panel without fins. The average electrical efficiency of PV panel with fins was $15.3 \%$, which was $0.3 \%$ higher than that of PV panel without fins.

Fig. 5 showed the variation of power output under different ambient temperatures. It can be seen from Fig. 5 that the power output decreased with the increasing ambient temperature. As the ambient temperature increased from $42.8{ }^{\circ} \mathrm{C}$ to $52.8{ }^{\circ} \mathrm{C}$, the power output decreased from $61.7 \mathrm{~W}$ to $59.6 \mathrm{~W}$ for PV panel with fins, while from $60.6 \mathrm{~W}$ to $58.7 \mathrm{~W}$ for PV panel without fins. The average power outputs of PV panel with and without fins were $60.7 \mathrm{~W}$ and $59.6 \mathrm{~W}$ respectively. The former was $1.8 \%$ higher 
than the latter.

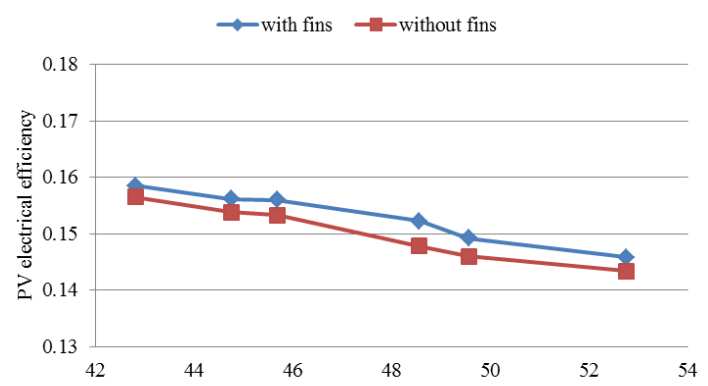

Fig. 4. Variation of electrical efficiency with ambient temperature.

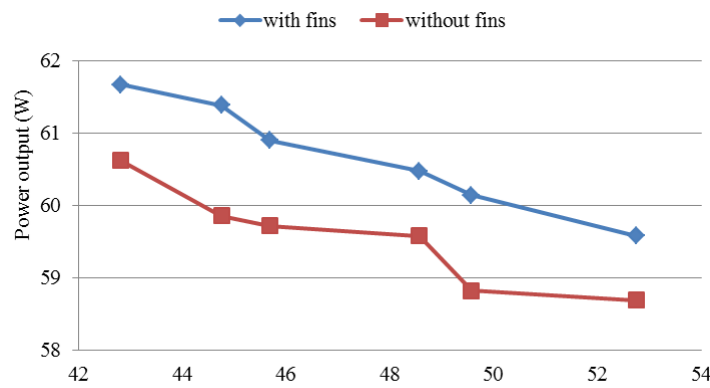

Fig. 5. Variation of power output with ambient temperature.

\subsection{Effect of wind velocity on electrical efficiency and power output}

The investigation on the effect of wind velocity on the electrical efficiency and power output was carried out based on the testing mode C. Fig. 6 showed the variation of PV electrical efficiency under different wind velocities. Higher wind velocity led to better fin cooling and consequently better PV electrical performance. The electrical efficiencies were $17.7 \%$ and $15.1 \%$ for PV panel with and without fins respectively at the wind velocity of $1 \mathrm{~m} / \mathrm{s}$. As the wind velocity increased to $3 \mathrm{~m} / \mathrm{s}$, the efficiencies increased to $18.9 \%$ and $17.9 \%$ respectively. The average electrical efficiency of PV panel with fins was $1.8 \%$ higher than that of PV panel without fins.

Fig. 7 showed the variation of power output under different wind velocities. It can be seen from Fig. 7 that the power output increased in linear with the increasing wind velocity. The power outputs were 45.4 $\mathrm{W}$ and $39.3 \mathrm{~W}$ for PV panel with and without fins respectively at the wind velocity of $1 \mathrm{~m} / \mathrm{s}$. As the wind velocity increased to $3 \mathrm{~m} / \mathrm{s}$, the power outputs increased to $53.9 \mathrm{~W}$ and $49.6 \mathrm{~W}$ respectively. The average power outputs of PV panel with and without fins were $49.2 \mathrm{~W}$ and $44 \mathrm{~W}$.
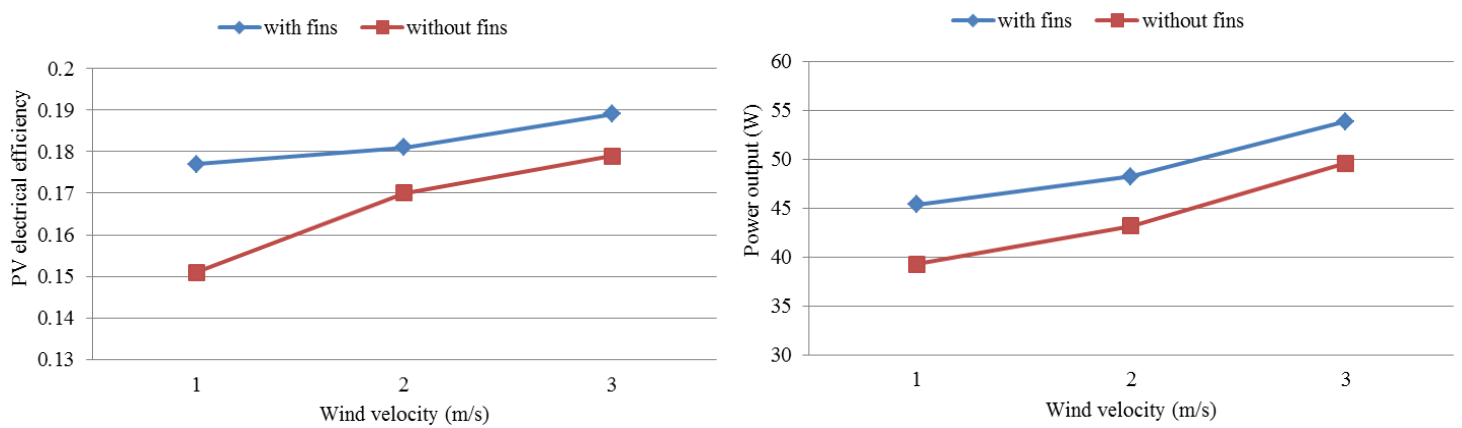

Fig. 6. Variation of electrical efficiency with wind velocity. Fig. 7. Variation of power output with wind velocity.

\subsection{Effect of solar radiation on electrical efficiency and power output}

The investigation on the effect of solar radiation on the electrical efficiency and power output was carried out based on the testing mode D. In order to investigate the effect of solar radiation instead of other factors, the tested data under the same ambient temperature and wind velocity but different solar radiation were chosen for analysis. Obviously, the changing range of solar radiation was limited and small at the same ambient temperature and wind velocity. Fig. 8 showed the variation of electrical efficiency under different solar radiation. It can be seen from Fig. 8 that the electrical efficiency decreased with the increasing solar radiation. As the solar radiation increased from $300 \mathrm{~W} / \mathrm{m}^{2}$ to $480 \mathrm{~W} / \mathrm{m}^{2}$, the electrical efficiency decreased from $17.4 \%$ to $16.5 \%$ for PV panel with fins, while from $17.3 \%$ to $15.9 \%$ for PV panel without fins. The average electrical efficiencies of PV panel with and without fins were $17.2 \%$ and 
$16.7 \%$, respectively.

Fig. 9 showed the variation of power output under different solar radiation. It can be seen from Fig. 9 that the power output increased with the increasing solar radiation. As the solar radiation increased from $300 \mathrm{~W} / \mathrm{m}^{2}$ to $480 \mathrm{~W} / \mathrm{m}^{2}$, the power output increased from $40.4 \mathrm{~W}$ to $61.7 \mathrm{~W}$ for PV panel with fins, while from $40.2 \mathrm{~W}$ to $59.7 \mathrm{~W}$ for PV panel without fins. The average power output of PV panel with and without fins was $51.9 \mathrm{~W}$ and $50.7 \mathrm{~W}$.
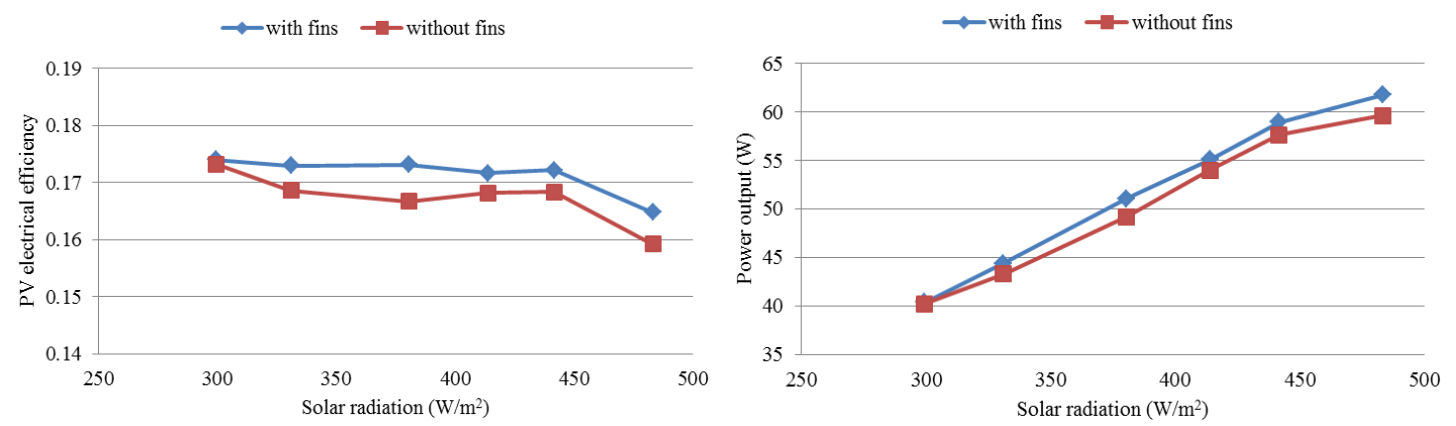

Fig. 8. Variation of electrical efficiency with solar radiation. Fig. 9. Variation of power output with solar radiation.

\section{Conclusions}

The paper presented an experimental study on the performance improvement of photovoltaic panel with passive cooling under natural ventilation. The rig of PV panel with cooling fins was constructed for the testing at the Beijing University of Civil Engineering and Architecture, China. Four testing modes were proposed to investigate the effect of PV panel inclination, solar radiation, and ambient temperature as well as wind velocity on the electrical efficiency and power output. The study could be concluded that:

1) The electrical efficiency decreased firstly and then increased with the increasing PV panel inclination. The power output increased firstly and then decreased with the increasing PV panel inclination. The average electrical efficiency and power output of PV panel with fins were $1.3 \%$ and $3.1 \%$ higher than that of PV panel without fins.

2) The electrical efficiency and power output decreased with the increasing ambient temperature. The average electrical efficiency and power output of PV panel with fins were $0.3 \%$ and $1.8 \%$ higher than that of PV panel without fins.

3) Higher wind velocity led to better fin cooling and consequently better PV electrical performance. The average electrical efficiency and power output of PV panel with fins were $1.8 \%$ and $11.8 \%$ higher than that of PV panel without fins.

4) The electrical efficiency decreased and the power output increased with the increasing solar radiation. The average electrical efficiency and power output of PV panel with fins were $0.7 \%$ and $2.4 \%$ higher than that of PV panel without fins.

\section{Acknowledgements}

The work of this paper is fully supported by Funding Project for New Star of Scientific and Technical Research of Beijing (2011029), The Importation and Development of High-Caliber Talents Project of Beijing Municipal Institutions (CIT\&TCD201304067) and Beijing Municipal Key Lab of HVAC.

\section{References}

[1] Skoplaki E, Palyvos JA. On the temperature dependence of photovoltaic module electrical performance: A review of efficiency/power correlations. Solar Energy, 2009; 83(5):614-624.

[2] Assoa YB, Menezo C, Fraisse G, Yezou R, Brau J. Study of a new concept of photovoltaic-thermal hybrid collector. Solar Energy, 2007; 81(9):1132-1143. 
[3] Zondag H. Flat-plate PV-thermal collectors and systems: A review. Renew Sust. Energ Rev., 2008; 12(4):891-59.

[4] Tobias I, delCanizo C, Alonso J. Crystalline silicon solar cells and modules. In: Luque A, Hegedus S (editors). Handbook of Photovoltaic Science and Engineering. Wiley 2003:ch. 7.

[5] Chow T. Performance analysis of photovoltaic-thermal collector by explicit dynamic model. Solar Energy, 2003; 75(2):14352.

[6] Yamawaki T, Mizukami S, Masui T, et al. Experimental investigation on generated power of amorphous PV module for roof azimuth. Solar Energy Materials and Solar Cells, 2001; 67(1-4):369-77.

[7] PVT Roadmap - A European Guide for the Development and Market Introduction of PV-Thermal Technology. (2006). PVT forum. [Online]. Available: http://www.pvtforum.org/index.html

[8] Tiwari A, Sodha MS. Performance evaluation of a solar PV/T system: An experimental validation. Solar Energy, 2006; 80(7):751-59.

[9] Chow T, He W, Ji J. Hybrid photovoltaic-thermosyphon water heating system for residential application. Solar Energy, 2006; 80(3):298-306.

[10] Ji J, Liu K, Chow T, Pei G, He W, He H. Performance analysis of a photovoltaic heat pump. Applied Energy, 2008; 85(8):680-693

[11] Ji J, Pei G, Chow T, Liu K, He H, Lu J, Han C. Experimental study of photovoltaic solar assisted heat pump system. Solar Energy, 2008; 82(1):43-52.

[12] Liu K, Ji J, Chow T, Pei G, He H, Jiang A, Yang J. Performance study of a photovoltaic solar assisted heat pump with variable-frequency compressor - A case study in Tibet. Renewable Energy, 2009; 34(12):2680-2687. 